\title{
INFERIOR TURBINECTOMY VERSUS SUBMUCOSAL DIATHERMY- OUR EXPERIENCE
}

\author{
Siva Subba Rao Pakanati ${ }^{1}$, E. Pratik Edwards², S. Chandramouli 3 , J. Durga Bhavani ${ }^{4}$ \\ ${ }^{1}$ Associate Professor, Department of ENT, Mamata Medical College, Khammam. \\ ${ }^{2}$ Postgraduate Student, Department of ENT, Mamata Medical College, Khammam. \\ ${ }^{3}$ Postgraduate Student, Department of ENT, Mamata Medical College, Khammam. \\ ${ }^{4}$ Postgraduate Student, Department of ENT, Mamata Medical College, Khammam.
}

\section{ABSTRACT}

\section{BACKGROUND}

The objective of this study is to compare and evaluate the results of Bilateral Inferior Turbinectomy (BIT) and Submucosal Diathermy (SMD) in case of bilateral hypertrophied inferior turbinates with nasal obstruction.

\section{MATERIALS AND METHODS}

This is a non-randomised controlled trial, involved 50 patients with bilateral nasal obstruction and bilateral hypertrophied inferior turbinates, divided into two groups. 25 patients underwent bilateral turbinectomy and 25 patients underwent SMD. All the 50 patients were followed for 2 months after surgery.

\section{RESULTS}

Post-operative improvement in nasal breathing after BIT was reported for $96 \%$ patients, 2 weeks after surgery and for $88 \%$ after 2 months. SMD showed good results in $76 \%$ of cases two weeks after surgery and improvement was reduced to $72 \%$ two months after surgery.

\section{CONCLUSION}

Both the procedures, bilateral inferior turbinectomy and submucosal diathermy are effective in reducing nasal obstruction caused by bilateral hypertrophied inferior turbinates. Although SMD is effective, still it could be disappointing on long-term basis.

\section{KEYWORDS}

Inferior Turbinectomy, Submucosal Diathermy, Nasal Obstruction.

HOW TO CITE THIS ARTICLE: Pakanati SSR, Edwards EP, Chandramouli S, et al. Inferior turbinectomy versus submucosal diathermy- our experience. J. Evolution Med. Dent. Sci. 2017;6(46):3568-3570, DOI: 10.14260/Jemds/2017/769

\section{BACKGROUND}

Nasal obstruction is common in the adult population and is associated with mouth breathing, oropharyngeal dryness, disordered sleep and adversely affects the quality of life.1,2 The cause of chronic nasal obstruction due to hypertrophied inferior turbinates is usually allergic rhinitis or vasomotor rhinitis. The turbinate enlargement in these patients is usually bilateral and is due to thickening of the mucosa without hypertrophy of the underlying structures. ${ }^{3}$

Most cases of inferior turbinate hypertrophy are amenable to medical treatment including antihistamines, topical and systemic steroids and allergen avoidance. But if these measures fail, surgery is advised. A variety of different surgical techniques have been described for the treatment of inferior turbinate hypertrophy. These include turbinectomy, turbinoplasty, submucous resection, electrocautery, chemical cautery, coblation and laser. ${ }^{4}$ Inferior turbinectomy was first reported in $1895^{5}$ and five years later Holmes reported his experience with turbinectomy in 500 patients. ${ }^{6}$ Unfortunately, these procedures are traumatic and often complicated by bleeding, dryness, crusting and the

Financial or Other, Competing Interest: None.

Submission 01-05-2017, Peer Review 25-05-2017,

Acceptance 01-06-2017, Published 08-06-2017.

Corresponding Author:

Dr. Siva Subba Rao Pakanati,

Department of ENT,

Mamata General Hospital,

Khammam-507002, Telangana State.

E-mail: pakanati.sivasubbarao@gmail.com

DOI: $10.14260 /$ jemds $/ 2017 / 769$ controversy over the safety of resection of the inferior turbinates has continued to this day.

Submucosal Diathermy (SMD) of the inferior turbinates was reported in 1907.7 It was believed that the coagulative current produces tissue necrosis and then fibrosis, causing shrinkage of the soft tissues of the turbinates. ${ }^{8}$ SMD is a simple and effective way of reduction surgery on the hypertrophied inferior turbinates. It was found to be very effective in alleviating chronic nasal obstruction due to hypertrophy of the inferior turbinate. ${ }^{9}$ The objective of this study is to compare and evaluate the results of Bilateral Inferior Turbinectomy (BIT) and Submucosal Diathermy (SMD) in case of bilateral hypertrophied inferior turbinates with nasal obstruction.

\section{MATERIALS AND METHODS}

Study Design

Non-Randomised Controlled Trial.

\section{Setting}

This study has been conducted in the Dept. of ENT, Mamata Medical College, Khammam.

\section{Study Period}

One and a half year from July 2015 to December 2016.

\section{Sample Size}

All the patients with chief complaint of nasal obstruction around 170 were reviewed in ENT OPD, but only 50 patients underwent the study out of 67 patients met the inclusion criteria of the study. 


\section{Inclusion Criteria}

Patients with bilateral nasal obstruction and bilateral hypertrophied inferior turbinates suffered from allergic rhinitis or vasomotor rhinitis.

\section{Exclusion Criteria}

Patients with deviated nasal septum, nasal polyposis, chronic sinusitis and who had undergone prior nasal surgery were excluded from the study. Patients apart from nasal obstruction, also suffering from significant sneezing, nasal discharge were also excluded from the study. After all these exclusions, 67 patients met the inclusion criteria.

\section{Method of Allocation}

A total of 170 patients were reviewed in the Dept. of ENT, Mamata Medical College, Khammam with chief complaint of nasal obstruction during the study period. The patients who met the inclusion criteria, irrespective of their age, sex and their nasal airflow (measured by Glatzel mirror) underwent the study modalities BIT and SMD alternately. Even though 67 patients met the inclusion criteria, 12 patients rejected for BIT or SMD and 5 patients after giving their willingness did not turn back. So at the end of the study, only 50 patients were available and they were alternately allocated to the study modalities BIT or SMD.

SMD was performed under topical anaesthesia using $4 \%$ xylocaine with adrenaline and by using $2 \mathrm{~mL}$ of $2 \%$ xylocaine with adrenaline (1:100000) for local infiltration. A diathermy needle was inserted into the anterior end of the inferior turbinate and advanced up to the posterior end submucosally. The needle was withdrawn over a period of 15 seconds with the current applied. This procedure was performed twice on each inferior turbinate.

Bilateral Inferior Turbinectomy (BIT) was carried out under local anaesthesia, same as it was for SMD and turbinectomy was carried by angled scissors. After excision, the nasal airways were packed with soframycin nasal packs, which were removed 48 to 72 hours after the operation. Both BIT and SMD were performed in the operation room under the supervision of senior anaesthetist.

All the patients who underwent SMD and BIT have been instructed for two postoperative assessments. The first postoperative assessment was made two weeks after the operation, the second one after two months. Each assessment included the subjective assessment about breathing through the nose and nasal air flow measurement with the Glatzel mirror (which is a $20 \times 13 \mathrm{~cm}$, stainless steel metal plate with markings to measure the condensation of exhaled air on a cold metal surface - $>5 \mathrm{~cm}$ is considered as improvement $)^{10}$ apart from anterior and posterior rhinoscopy.

\section{Statistical Methods}

The data were analysed by using chi-square test of independence. The significance was set at 5\% level of significance $(P<0.05)$. The software used is SPSS 20.0 version.

\section{RESULTS}

The first postoperative assessment was done two weeks after surgery. At this stage, 24 patients (96\%) who underwent Bilateral Inferior Turbinectomy (BIT) reported improvement in nasal breathing and 19 patients (76\%) who underwent
SMD reported improvement in nasal breathing; 1 BIT patient (4\%) and 6 SMD patients (24\%) reported no improvement.

\begin{tabular}{|c|c|c|c|c|}
\hline \multirow{2}{*}{$\begin{array}{c}\text { State of Nasal } \\
\text { Breathing }\end{array}$} & \multicolumn{2}{|c|}{ BIT } & \multicolumn{2}{c|}{ SMD } \\
\cline { 2 - 5 } & No & \% & No & \% \\
\hline Free Breathing & 12 & 48 & 8 & 32 \\
\hline $\begin{array}{c}\text { Significant } \\
\text { Improvement }\end{array}$ & 9 & 36 & 9 & 36 \\
\hline Mild Improvement & 3 & 12 & 2 & 8 \\
\hline No Improvement & 1 & 4 & 6 & 24 \\
\hline Chi-square $=4.5712, \mathrm{P}=0.2061$ \\
\hline $\begin{array}{r}\text { Table 1. Subjective Assessment of } \\
\text { Nasal Breathing Two Weeks after Surgery }\end{array}$ \\
\hline
\end{tabular}

The results of airflow measurements made by Glatzel mirror 2 weeks after surgery are summarised in Table 2 .

\begin{tabular}{|c|c|c|c|c|}
\hline \multirow{2}{*}{$\begin{array}{c}\text { Nasal Breathing } \\
\text { (cm) }\end{array}$} & \multicolumn{2}{|c|}{ BIT } & \multicolumn{2}{c|}{ SMD } \\
\cline { 2 - 5 } & No & $\mathbf{\%}$ & No & $\%$ \\
\hline $0-1$ & 0 & 0 & 0 & 0 \\
\hline $2-3$ & 1 & 4 & 1 & 4 \\
\hline $4-5$ & 1 & 4 & 4 & 16 \\
\hline $6-7$ & 6 & 24 & 8 & 32 \\
\hline $8-9$ & 17 & 68 & 12 & 48 \\
\hline \multicolumn{4}{|c|}{ Chi-square $=2.4323, \mathrm{P}=0.2961$} \\
\hline
\end{tabular}

The next postoperative assessment was made two months after surgery. At this stage, 22 BIT patients (88\%) and 18 SMD patients (72\%) reported improvement in breathing. But 3 BIT patients (12\%) and 7 SMD patients $(28 \%)$ reported no improvement in nasal breathing.

\begin{tabular}{|c|c|c|c|c|}
\hline \multirow{2}{*}{$\begin{array}{c}\text { State of Nasal } \\
\text { Breathing }\end{array}$} & \multicolumn{2}{|c|}{ BIT } & \multicolumn{2}{c|}{ SMD } \\
\cline { 2 - 5 } & No & $\%$ & No & $\%$ \\
\hline Free Breathing & 20 & 80 & 16 & 64 \\
\hline $\begin{array}{c}\text { Significant } \\
\text { Improvement }\end{array}$ & 1 & 4 & 1 & 4 \\
\hline Mild Improvement & 1 & 4 & 1 & 4 \\
\hline No Improvement & 3 & 12 & 7 & 28 \\
\hline Chi-square= 2.0442, P= 0.5631 \\
\hline $\begin{array}{r}\text { Table 3. Subjective Assessment of Nasal Breathing Two } \\
\text { Months after Surgery }\end{array}$
\end{tabular}

The results of airflow measurements made by Glatzel mirror 2 months after surgery are summarised in Table 4 .

\begin{tabular}{|c|c|c|c|c|}
\hline \multirow{2}{*}{$\begin{array}{c}\text { Nasal Breathing } \\
\text { (cm) }\end{array}$} & \multicolumn{2}{|c|}{ BIT } & \multicolumn{2}{c|}{ SMD } \\
\cline { 2 - 5 } & No & $\mathbf{\%}$ & No & \% \\
\hline $0-1$ & 0 & 0 & 0 & 0 \\
\hline $2-3$ & 1 & 4 & 3 & 12 \\
\hline $4-5$ & 2 & 8 & 4 & 16 \\
\hline $6-7$ & 8 & 32 & 8 & 32 \\
\hline $8-9$ & 14 & 56 & 10 & 40 \\
\hline \multicolumn{4}{|c|}{ Chi-square $=2.3323, \mathrm{P}=0.5062$} \\
\hline $\begin{array}{c}\text { Table 4. Objective Assessment of Nasal Airflow by } \\
\text { Glatzel Mirror Two Months after Surgery }\end{array}$
\end{tabular}




\section{DISCUSSION}

Nasal obstruction, usually the most common presenting symptom was encountered by otolaryngologists. ${ }^{11}$ Most patients with nasal obstruction have turbinate hypertrophy due to vasomotor or allergic rhinitis. Most cases responded to medical treatment, but in some cases surgery is required.11

The surgical treatment is controversial and many surgical methods of treatment have been proposed. ${ }^{12}$

In the present work, we compared 2 widespread methods of turbinate reduction for inferior turbinate hypertrophy, BIT and SMD in 50 patients. Before surgery, we could not predict the outcome of study modalities. At the end of the study, there was no significant difference $(P>0.05)$ between outcome in terms of nasal obstruction for the two methods. A partial failure of the SMD technique could result if the diathermy needle did not reach the posterior end of the inferior turbinate.

The long-term effectiveness of inferior turbinectomy was assessed by Ophir et al, ${ }^{12}$ who reported improvement of nasal obstruction in $82 \%$ of patients and these results are similar to our study where the improvement by BIT was $88 \%$. Submucous Diathermy (SMD) of the inferior turbinate was found very effective in relieving nasal obstruction in our patients, $76 \%$ is comparable to findings by Fradis et al, i.e. $78 \%{ }^{13}$

SMD can be carried out under local anaesthesia and can be implemented as an OPD procedure. It does not require expensive instrumentation and is safe and effective procedure, especially in short-term, but BIT cannot be performed in OPD. It should be performed in operation theatre only, because of the risk of heavy bleeding and is an effective procedure for improving nasal obstruction in patients with chronic hypertrophied inferior turbinates, both in the short and long terms.

\section{CONCLUSION}

Both procedures BIT and SMD are relatively safe and effective in relieving nasal obstruction, caused by hypertrophied inferior turbinates. Although, SMD is more effective in the short term, could be disappointing on a long-term basis. In spite of controversial complications like atrophic rhinitis and empty nose syndrome, still BIT can be an effective option for bilateral hypertrophied inferior turbinates causing nasal obstruction, especially in allergic rhinitis or vasomotor rhinitis patients.

\section{REFERENCES}

[1] Willatt D. The evidence for reducing inferior turbinates. Rhinology 2009;47(3):227-36.

[2] Enache A, Lieder A, Issing W. Nasal septoplasty with submucosal diathermy to inferior turbinates improves symptoms at 3 months post operatively in a study of one hundred and one patients. Clin Otolaryngol 2014;39(1):57-63.

[3] Rakover Y, Rosen G. A comparison of partial inferior turbinectomy and cryosurgery for hypertrophic inferior turbinates. J Laryngol Otol 1996;110(8):732-5.

[4] Passali D, Lauriello M, De Filippi A, et al. Comparative study of most recent surgical techniques for the treatment of the hypertrophy of inferior turbinates. Acta otorhinolaryngol Hal 1995;15(3):219-28.

[5] Jones M. Turbinai hypertrophy. Lancet 1895;2:879-82.

[6] Holmes CR. Hypertrophy of the turbinated bodies. NY Med J 1900; 72: 529-32.

[7] Neres FE. Voltaic: turbinal puncture for the relief of intumescent and hypertrophic rhinitis. J Am Med ASSOC 1907; 49: 1435-8.

[8] Woodhead CJ, Wickham MH, Smelt GJC, et al. Some observations on submucous diathermy. J Laryngol Otol 1989;103(11):1047-9.

[9] Passali D, Passali FM, Damiani V, et al. Treatment of inferior turbinate hypertrophy: a randomized clinical trial. Ann Otol Rhinol Laryngol 2003;112(8):683-8.

[10] Marchesan IQ. Protocol de avaliacao miofuncional orofacial. In: Respiracao oral. Krakauer LH, Di Francesco Rc e Marchesan IQ (org) Sao Jose dos caropos: Pulso Editorial 2003:55-80.

[11] Goldshei M, Joachims HZ, Golz A, et al. Nd: YAG laser turbinate surgery animal experimental study: preliminary report. Laryngoscope 1995;105(3 Pt 1):319-21.

[12] Ophir D, Schindel D, Halperin D, et al. Long-term follow up of the effectiveness and safety of inferior turbinectomy. Plast Reconstr Surg 1992;90(6):980-7.

[13] Fradis M, Malalskey S, Magamsa I, et al. Effect of submucosal diathermy in chronic nasal obstruction due to turbinate enlargement. Am J Otolaryngol 2002;23(6):332-6. 